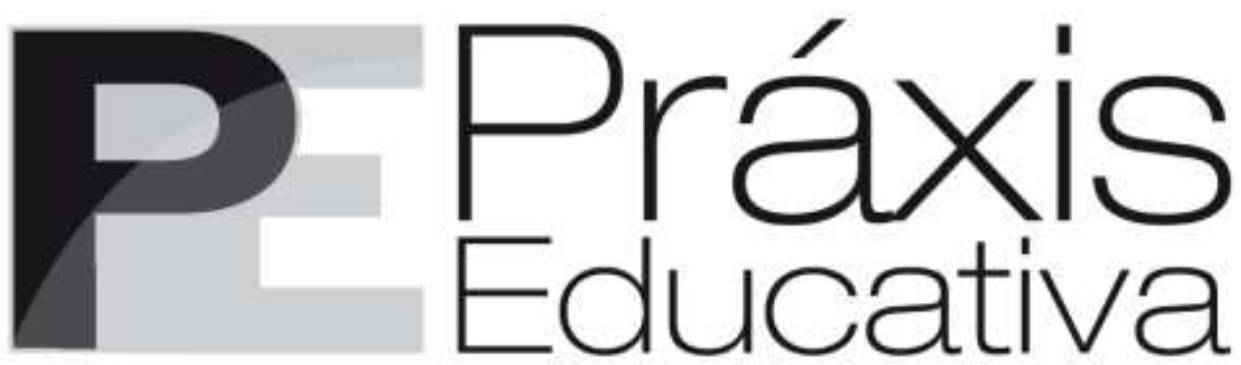

ISSN 1809-4031

elSSN 1809-4309

https://doi.org/10.5212/PraxEduc.v.17.18510.023

Seção: Artigos

\title{
A função do "Novo" Ensino Médio na lógica do capital: estratificação, perspectivas e resistências
}

\section{The role of the "New" High School in the logic of capital: stratification, perspectives and resistances}

\section{E1 papel de la Escuela Secundaria "Nueva" en la lógica del capital: estratificación, perspectivas y resistencias \\ Mike Ceriani de Oliveira Gomes* \\ https://orcid.org/0000-0002-7039-1137}

Resumo: Este artigo tem como objetivo refletir as mudanças no sistema de educação formal brasileiro. Foi utilizada como ponto de partida para a análise bibliográfica uma citação da obra $A$ educaşão para além do capital, do filósofo húngaro István Mészáros, na qual este cita um modelo educacional arcaico sugerido pelo filósofo iluminista inglês John Locke para as classes populares. Dessa maneira, foram discutidos os processos educacionais acríticos, de caráter alienador, e os processos educacionais críticos, de caráter formador e seu antagonismo aos modelos pedagógicos vocacionais, modernizados ao longo da história, mas sempre dentro da mesma lógica de reprodução de desigualdades do sistema capitalista. Ao final, o modelo acrítico e seu desdobramento são contextualizados na Lei No 13.415, de 16 de fevereiro de 2017, do Novo Ensino Médio, bem como a articulação dos principais agentes de interesse nessa Lei.

Palavras-chave: Classes dominantes. Classes populares. Novo Ensino Médio.

\begin{abstract}
This paper aims to reflect the changes in the Brazilian formal education system. As a starting point for the bibliographic analysis a quote from the book Education beyond capital, by the Hungarian philosopher István Mészáros, was used to describe an archaic educational model suggested by the English Enlightenment philosopher John Locke for the popular classes. In this way, it was discussed the uncritical educational processes, of alienating character, and critical educational processes, of formative character and their antagonism to vocational pedagogical models, modernized throughout history, but always within the same logic of reproducing inequalities of the capitalist system. In the end, the uncritical model and its unfolding are contextualized in Law no. 13.415, of February 16, 2017, of the Brazilian New High School, as well as the articulation of the main agents of interest in this law.
\end{abstract}

Keywords: Ruling classes. Popular classes. New High School.

\footnotetext{
* Mestrando em Educação pela Universidade Estadual Paulista (Unesp), Campus Marília. E-mail: <mikegd1@hotmail.com>e/ou <mike.ceriani@unesp.br>.
} 
Resumen: Este artículo tiene como objetivo reflexionar sobre los cambios en el sistema de educación formal brasileño. Fue utilizada como punto de partida para el análisis bibliográfico una cita de la obra La educación más allá del capital, del filósofo húngaro István Mészáros, en la que éste cita un modelo educativo arcaico sugerido por el filósofo iluminista inglés John Locke para las clases populares. De esa manera, fueron discutidos los procesos educativos acríticos, de carácter alienante, y los procesos educativos críticos, de carácter formativo y su antagonismo con los modelos pedagógicos vocacionales, modernizados a lo largo de la historia, pero siempre dentro de la misma lógica de reproducción de desigualdades del sistema capitalista. Al final, el modelo acrítico y su desenvolvimiento son contextualizados en la Ley $\mathrm{N}^{\circ} 13.415$, del 16 de febrero de 2017, de la Nueva Educación Secundaria, así como la articulación de los principales agentes de interés en esta ley.

Palabras clave: Clases dominantes. Clases populares. Nueva Educación Secundaria.

\section{Introdução}

Este artigo tem sua construção idealizada a partir de discussões acerca da educação como área de interesse de diversos grupos da esfera social e política, de modo que possa explicar, por meio de uma leitura de autores das Ciências Humanas, como ocorrem as dinâmicas sociais que conduzem o poder público, mediante lobbies, a definir meios e objetivos para a gestão da educação pública.

No Brasil e no mundo, sucessos e insucessos são frequentemente postos com modelos pedagógicos na intenção de apontar responsáveis para tanto. Os valores que inicialmente motivam críticos de modelos educacionais muitas vezes estão nos rankings internacionais, tendo o Programme for International Student Assessment, o Pisa, elevado protagonismo nesse processo desde a adesão brasileira a ele, requisito para o país ao estar interessado em integrar a Organisation de Coopération et de Développement Économiques, a OCDE. Entretanto, não é encontrada no Pisa uma base de sustentação para qualquer direção a ser tomada na busca por resoluções aos problemas educacionais brasileiros em um contexto nacional alheio aos interesses da OCDE (ARAÚJO; TENÓRIO, 2017).

À parte de índices que desconsideram fatores como a desigualdade de oportunidades dentro de uma sociedade de classes, tal como é o Pisa, a discussão sobre os rumos que devem tomar a educação em um país onde notoriamente as condições materiais são cada vez mais determinantes para o acesso ao Ensino Superior ainda limita, por um lado, seus olhares aos modelos formais tradicionais, dentro de estruturas que mantêm o sistema desigual vigente. Por outro lado, autores da área da Sociologia da Educação, como Paulo Meksenas (2014), oferecem novas ópticas ao sistema educacional, partindo de questionamentos mais aprofundados, tais como quem se serve da educação, não a partir de sua qualidade, mas de seu sistema administrativo, e, com isso, expõem sua dualidade histórica.

Diferentemente das categorias sociais que não se beneficiam de um modelo burguês e necessitam reconhecer e escancarar essa dualidade, classes mais abastadas apenas contam com a missão de garantir a perpetuação do status quo pela despolitização das classes menos favorecidas. Em uso de seu poder de barganha com esferas públicas, é facilitada a ampliação dessa despolitização, fazendo-a chegar ao seio escolar. Tal processo ficou muito claro, por exemplo, com a sanção da Lei $\mathrm{N}^{0}$ 13.415, de 16 de fevereiro de 2017, responsável pela reorganização curricular do Ensino Médio brasileiro (BRASIL, 2017).

Carregada de propaganda em tom progressista, essa Lei é apresentada como proposta de modernização do sistema educativo, tomando referências de países desenvolvidos, tais como Inglaterra, França, Coreia do Sul, Portugal e Austrália. Sua principal característica é a adoção de

Práxis Educativa, Ponta Grossa, v. 17, e2218510, p. 1-16, 2022 Disponível em: < https://revistas2.uepg.br/index.php/praxiseducativa $>$ 
uma grade curricular mais flexiva, de acordo com os interesses de alunos que visam formações diversificadas, contendo a opção pela formação profissionalizante a quem aspira a um ingresso imediato ao mercado de trabalho em vez do Ensino Superior e de ter na escola uma formação qualitativa para o questionamento e o confronto com as estruturas que resultam em suas condições sociais, condições que naturalmente se potencializariam pela abertura de espaços às classes mais privilegiadas nas universidades. Segundo Hernandes (2019),

[...] a quinta opção [de estrutura curricular], formação técnica e profissional, nada tem a
ver com os conteúdos escolares. Escolas com maior poder aquisitivo, notadamente as
particulares, poderão oferecer os quatro arranjos curriculares similares à BNCC, ou seja,
os conteúdos escolares, que inclusive constituem a base para os processos seletivos para
acesso ao ensino superior, bem como conteúdos básicos para a permanência dos
estudantes nessa modalidade de ensino. As escolas "remediadas" poderão compor e
organizar quais e quantos arranjos curriculares puderem, ou seja, oferecerão itinerários
formativos remediados. (HERNANDES, 2019, p. 7).

A dualidade na educação pública tampouco é uma novidade partida da Lei No 13.415/2017. A promoção do ensino acrítico para a mera qualificação ao trabalho alienado sempre foi uma agenda defendida até mesmo pelos chamados "iluminados" da filosofia, dentre os quais John Locke, como menciona em um artigo enfatizando sua posição a favor de uma pedagogia adestradora:

Os filhos das pessoas trabalhadoras são um corriqueiro fardo para a paróquia, e normalmente são mantidas na ociosidade, de forma que geralmente também se perde o que produziram para a população até eles completarem doze ou catorze anos de idade. Para esse problema, a solução mais eficaz que somos capazes de conceber, e que portanto humildemente propomos, é a de que, na acima mencionada lei a ser decretada ${ }^{1}$, seja determinado, além disso, que se criem escolas profissionalizantes em todas as paróquias, as quais os filhos de todos, na medida das necessidades da paróquia, entre quatro e treze anos de idade, devem ser obrigados a frequentar. (LOCKE, 1876, p. 383 apud MÉSZÁROS, 2008 , p. 41-42, grifos do autor).

Tido como o "pai do liberalismo", John Locke (1632-1704) viveu a transição do feudalismo para o capitalismo, e ainda que novas leis com uma roupagem modernizada ganhem protagonismo no século XXI, diversos elementos evidenciam que a perpetuação do modelo servil burguês está clara nas estruturas sociais, cujas dinâmicas são passíveis de observações logo nos sistemas de gestão escolar. Dessa maneira, a obra $A$ educaşão para além do capital, do filósofo húngaro István Mészáros (2008), foi tomada como ponto de partida, objetivando juntamente a revisões de obras de outros autores e de outras autoras, análises críticas às ameaças que vêm sofrendo a escola com a ascensão da agenda neoliberal, especificamente em território brasileiro. Portanto, esta é uma pesquisa de metodologia bibliográfica e documental, de natureza qualitativa explicativa.

\section{A educação para o trabalho em duas perspectivas}

A discussão que circunda o tema "educação para o trabalho" deve, a princípio, responder a uma indagação presente logo no texto introdutório deste artigo: Quem se serve da educação? Para chegar à formulação dessa pergunta, é necessário, antes de tudo, entender que a educação cumpre uma função social, capaz de atender a determinados agentes de interesses de acordo com a sua direção (MEKSENAS, 2014). Quando então dialoga com o trabalho, a educação pode assumir duas direções: a acrítica, dentro das estruturas sociais estabelecidas, ou seja, do status quo; e

\footnotetext{
${ }^{1}$ Lei decretada pelo Rei Henrique VIII (1491-1547) que previa o açoitamento e o corte de metade de uma orelha como punição aos chamados “vagabundos” (criminosos) reincidentes (MÉSZÁROS, 2008, p. 41).
}

Práxis Educativa, Ponta Grossa, v. 17, e2218510, p. 1-16, 2022 Disponível em: < https://revistas2.uepg.br/index.php/praxiseducativa $>$ 
a crítica, de caráter libertador, que seria, em essência, uma educação que tem como função a transformação da ordem vigente.

Pensar a educação acrítica junto à indagação sobre quem se serve dela permite uma compreensão mais clara sobre seu papel no trabalho a partir da crítica marxista ao sistema de produção capitalista, sendo essencialmente a mercantilização da força de trabalho uma necessidade para a acumulação primitiva, ou seja, a condição de enriquecimento da classe burguesa mediante exploração e alienação do trabalho (MARX, 1996). Essa observação é responsável por formular o pensamento de Mészáros, entre outros pensadores, a princípio, na concepção das críticas à exploração nas relações de trabalho e, posteriormente, na necessidade de um sistema de educação acrítico, baseado no treinamento para o trabalho alienado.

Em $A$ educação para além do capital, Mészáros resgata esse aspecto em Locke, não apenas por sua crítica à proposta de um modelo de educação profissionalizante de caráter adestrador, mas também pela concepção do filósofo inglês da classe trabalhadora.

[...] o crescimento do número dos pobres [...] nada mais é do que o relaxamento da disciplina e a corrupção dos hábitos; a virtude e a diligência são como companheiros constantes de um lado, assim como o vício e a ociosidade estão do outro. Portanto, o primeiro passo no sentido de fazer os pobres trabalhar $($ sic $)[. .$.$] deve ser a restrição de sua$ libertinagem mediante a aplicação estrita das leis estipuladas [por Henrique VIII e outros] contra ela. (LOCKE, 1876, p. 378 apud MÉSZÁROS, 2008, p. 39-40).

A posição de Locke sobre o controle do trabalhador predestinado à venda da força de trabalho em função dos interesses de acumulação primitiva da burguesia torna-se cada vez mais passível de contraposições de caráter moral com o passar do tempo e com as constantes mudanças nas relações de trabalho, o que tiraria o poder estético da observação de Mészáros se não por um aspecto importante: não há, nessas mudanças, uma superação do sistema de dominação classista determinador da alienação do trabalho, uma vez que essas novas relações continuam seguindo as regras do capital.

Dentre essas regras, destaca-se o condicionamento pacífico do sujeito aos interesses das classes dominantes, de alguma maneira vislumbrando uma realização pessoal. Nesse contexto, torna-se cada vez mais fácil às classes dominantes terem as classes dominadas à sua disposição. Mészáros (2008, p. 59) reitera o cenário em que são vivenciadas "[...] condições de uma desumanizante alienação e de uma subversão fetichista do real estado de coisas dentro da consciência", um ambiente em que a exploração é romantizada, e as bases que dão sustento à lógica capitalista ficam cada vez mais fortes e intactas.

Trata-se de uma realidade na qual a educação não se apresenta como um campo contra o qual se luta, mas pelo qual se luta. Se no período feudal a lógica de Locke partia da ideia do castigo, da imposição do medo como forma de adestrar servos e marginalizados, no cenário do capitalismo (supostamente) moderno, as classes dominantes têm mantido essa lógica pelo controle e pela alienação da própria consciência da classe trabalhadora. Sendo a educação, portanto, uma ferramenta para romper essa lógica por meio da consciência de classes, as classes dominantes disputam esse território com o objetivo de imprimir na educação os seus próprios interesses, destacando-se, sobretudo, a perpetuação da lógica do capital, assim como os objetivos mais imediatos, como a qualificação de mão de obra para o trabalho, processo que, no Brasil, foi intensificado nos anos de 1950 com o avanço da indústria.

As primeiras reivindicações em território brasileiro que tornaram públicas e notórias as condições educacionais do país, sobretudo em termos de analfabetismo de jovens e de adultos, tiveram início nos anos de 1930, ainda na era Vargas, sem muito efeito, porém, até a primeira parte

Práxis Educativa, Ponta Grossa, v. 17, e2218510, p. 1-16, 2022 Disponível em: < https://revistas2.uepg.br/index.php/praxiseducativa $>$ 
da década de 1950, quando a intensiva expansão industrial demandava mão de obra qualificada, ao menos com noções básicas de escrita e de leitura para atender ao novo sistema de produção que vinha ganhando forma. Nesse contexto, a educação foi pensada como uma urgência do próprio Estado e da burguesia (nesse segundo grupo, tal urgência intensificou-se mais adiante); entretanto, descartou-se por completo um modelo educacional de classes, que tivesse como prioridade a formação ao mero treinamento (SAMPAIO, 2009).

É certo dizer que os modelos de alfabetização promovidos pelo Estado no período em questão não bastaram para que cessasse a luta por um modelo de educação antagônico à hegemonia burguesa, luta que passou a ter maior intensidade a partir do momento em que o Estado (e posteriormente a burguesia) percebeu, na educação, um campo de disputa de interesses, o que resultou no fortalecimento de movimentos sociais e de educadores militantes por modelos de alfabetização crítica (XAVIER, 2019).

Já na segunda metade dos anos de 1950, houve maior protagonismo de novas propostas de modelos de alfabetização crítica trazidos por educadores como Paulo Freire (1921-1997), cuja notoriedade compôs, até março de 1964, o Plano Nacional de Alfabetização. Contudo, o golpe militar de 1964 trouxe consigo a descrença do avanço de um projeto de alfabetização crítico e de uma educação de classes, forçando o exílio de lideranças políticas de esquerda, bem como artistas e educadores, como Freire. Esse período teve seu afrouxamento em 1979, com a anistia aos exilados políticos e aos agentes da repressão. Dessa maneira, foi possível o retorno de Freire ao país e a retomada de suas atividades em território nacional, como um educador e como um ininterrupto autor intelectual. Pouco a pouco, as medidas paliativas de alfabetização promovidas pela ditadura foram se mostrando cada vez mais ineficazes, possibilitando a ascensão dos movimentos sociais defensores e da crítica libertária (PINI, 2019).

O processo de redemocratização no Brasil trouxe de volta a esperança pelo avanço de uma educação para as classes populares. O ano de 1988 foi marcado pela promulgação de uma nova Constituição Federal que, dentre outros aspectos, garantia o exercício de liberdades políticas antes caçadas ou ameaçadas pela ditadura. Oito anos mais tarde, em 1996, o então Presidente da República Fernando Henrique Cardoso, o FHC, sancionou a Lei No 9.394, de 20 de dezembro de 1996, que estabelece as Diretrizes e Bases da Educação Nacional, a LDB, concebendo a educação como, dentro dos dispostos da própria Lei, um “[...] dever da família e do Estado, inspirada nos princípios de liberdade e nos ideais de solidariedade humana, [e que] tem por finalidade o pleno desenvolvimento do educando, seu preparo para o exercício da cidadania e sua qualificação para o trabalho" (BRASIL, 1996, n.p.), tendo também como um de seus princípios "[...] a liberdade de aprender, ensinar, pesquisar e divulgar a cultura, o pensamento, a arte e o saber" (BRASIL, 1996, n.p.).

Há, nesse processo, contudo, uma liberdade que em partes pode ser compreendida como ilusória, de caráter demasiadamente irrestrito. Um dos exemplos, que será mais bem aprofundado adiante, é a institucionalização do Ensino Fundamental a distância, que se apresenta na LDB como uma “[...] complementação da aprendizagem ou em situações emergenciais” (BRASIL, 1996, n.p.). Entretanto, na prática, o que tem ocorrido é a licenciosidade e a falta de planejamento para a distribuição dessa modalidade de ensino, que, em longo prazo, culminou na mercantilização do ensino, do Fundamental ao Superior (GIOLO, 2008). Em suma, mesmo com a garantia de liberdades políticas, inclusive em campo educacional, as articulações do Estado em detrimento de interesses burgueses não deixaram de ocorrer, tendo apenas assumido novas características, como a propaganda e o subsídio para a busca de um modelo educacional ainda dentro da lógica capitalista.

É dada a mesma sequência a essa lógica mesmo com a ascensão de quatro mandatos consecutivos de dois chefes de estado do Partido dos Trabalhadores (PT), ainda que sustentados

Práxis Educativa, Ponta Grossa, v. 17, e2218510, p. 1-16, 2022 Disponível em: <https://revistas2.uepg.br/index.php/praxiseducativa $>$ 
por diversas lideranças de esquerda. De fato, foram atingidas metas ousadas, como a criação de 14 universidades de administração federal no Governo Luiz Inácio Lula da Silva (2003-2011) e a expansão de vagas de Ensino Médio e Técnico, bem como a implantação de políticas de cotas raciais para o Ensino Superior no Governo Dilma Rousseff (2011-2016). Contudo, grandes metas de contenção de alunos no ensino básico ficaram muito limitadas a um aspecto quantitativo, a uma lógica ainda demasiadamente mercadológica (BITTAR; BITTAR, 2012; LIMA, 2012).

Pode-se dizer, portanto, que o governo do PT não rompeu com a lógica do capital. Ainda que com suas lideranças de esquerda, a agenda neoliberal teve progressiva continuidade, inclusive na educação. Nesse contexto, ainda que criticada por lideranças do próprio PT, a Lei $\mathrm{N}^{\circ}$ 13.415/2017, sancionada no Governo Michel Temer (2016-2019), pode ser vista como mais uma etapa da progressão da agenda neoliberal, com algumas características extras que podem engessar ainda mais a educação pública no Brasil à lógica do capital, a serem discutidas mais adiante.

\title{
Um olhar sobre a proposta de educação libertadora e seus desafios
}

Conforme foi apresentado no tópico anterior, a educação tem uma função social a ser cumprida para o trabalho, tendo essa função definida por classes dominantes ou por classes dominadas. Com isso, é importante enfatizar que a educação, em uma perspectiva libertadora, não se opõe ao trabalho, porém, em regra, se opõe ao modelo de trabalho alienado que defende as classes dominantes e que é sustentado por seu modelo de educação acrítico. Fora do sistema de educação formal, essa situação é facilmente percebida por algumas lideranças e por movimentos sociais que, entre outros fatores, se propõem a gerenciar modelos alternativos de educação, modelos não alheios, mas antagônicos à lógica do capital. Nessa direção, há um forte destaque ao modelo do Movimento dos Trabalhadores Rurais Sem Terra, o MST.

Sendo um empreendimento nascido a partir da luta do Movimento pela terra, na qual ele realiza seu trabalho e da qual extrai sua sobrevivência, as escolas do MST surgiram como alternativa ao sistema societário vigente. Dal Ri e Vieitez (2008) trouxeram pesquisas sobre os processos educativos em duas escolas do Movimento que, além de seguir a matriz curricular imposta pelo Ministério da Educação, acrescenta mais disciplinas de acordo com os interesses de desenvolvimento do Movimento, e ainda conta com uma metodologia baseada nos autores de maior referência em termos de promoção do pensamento crítico.

\begin{abstract}
Para o MST, a metodologia mais adequada ao ensino é aquela que parte da prática e se desenvolve em uma relação prática-teoria-prática. O Movimento acredita, ainda, que de nada adianta o professor insistir na transmissão de conteúdos se a criança não souber para que servem esses conteúdos. Dessa forma, para o MST, o processo educacional deve ser iniciado a partir da vivência das pessoas, levando-se em conta a sua experiência de organização, trabalho e relacionamento com os outros. Ao professor não cabe o papel de transmitir conteúdos, mas o de ser um facilitador da aprendizagem a partir das experiências vividas pelos alunos em sua comunidade. O processo de aprendizagem deve ser por meio da interação do aluno com o meio cultural e com a comunidade da qual faz parte e com a intervenção de um professor que medeie essa relação. (DAL RI; VIEITEZ, 2008, p. 232).
\end{abstract}

A escolha por uma análise particular do processo educativo a partir do MST vai de encontro à proposição de Mészáros (2008) sobre uma educação que vá além do capital a partir de uma proposta político-pedagógica que tenha como principal resultado o rompimento com a lógica do capital. Compactuamos com o autor que tal feito não pode ocorrer apenas pela educação, porém, igualmente, não ocorrerá sem ela. É nessa mesma linha de pensamento que segue Freire (2019a) com sua otimista e nada ingênua esperança em uma mudança, esperança que, segundo o próprio,

Práxis Educativa, Ponta Grossa, v. 17, e2218510, p. 1-16, 2022 Disponível em: < https://revistas2.uepg.br/index.php/praxiseducativa $>$ 
não deve ser ausente ao educador e à educadora que têm como fundamento de sua prática a indignação com o sistema de injustiças imposto como uma normalidade e ao qual se deve adaptar.

Paulo Freire e István Mészáros convergem em diversos aspectos, tais como a busca pelo rompimento com a lógica do capital não dentro, mas fora dos meios institucionais de educação, visto que são meios escravizados à agenda neoliberal, como já exposto. O papel das lutas populares, como as ocorridas nos movimentos sociais, ganha fundamental importância a partir da elaboração de uma contraconsciência, em outras palavras, uma desconstrução da aceitação ao modelo burguês imposto e adotado culturalmente. É nesse contexto que o modelo educacional empregado pelo MST pode mostrar que uma mudança a partir da educação é possível.

Além de uma organização forte e de ideais claramente definidas, o Movimento tem seu objetivo final e seus sonhos notadamente expressos em seus programas educacionais. Partindo desses ideais, o MST reivindica sua luta, uma luta explicitamente contra a ordem vigente, a lógica do capital que coloca os sem-terra em uma posição sobre a qual eles têm consciência e cuja lógica eles têm uma genuína vontade de mudar.

\begin{abstract}
$\mathrm{Na}$ construção de sua concepção educacional, assumidamente socialista, o MST reivindica uma postura consciente do sujeito; na verdade, o próprio ingresso na luta pela terra implicaria um ato de consciência. Suas ações e metodologias educacionais incorporam diferentes influências teóricas e alguns componentes ideológicos que impulsionam a trajetória de todos aqueles que se engajam na luta pela terra. Entre elas, são priorizadas algumas concepções marxistas e de matrizes cristãs, com destaque para aquelas que dizem respeito a uma educação para o trabalho; os postulados de Paulo Freire, particularmente os que dizem respeito à sua pedagogia do oprimido e do diálogo, estão muito presentes nas atividades educacionais envolvendo jovens e adultos, como também as concepções de que a terra somente esteja nas mãos de quem trabalha e de que a luta travada é pela construção de uma sociedade sem exploradores e explorados. (BAUER, 2016, p. 172).
\end{abstract}

Naturalmente, a luta também deve adentrar outros campos, outras realidades. O que se pode aproveitar, portanto, é o rigor científico do MST aliado à sua práxis pedagógica. Trata-se de um movimento que reivindica um radical rompimento com a lógica do capital também pela negação do discurso neoliberal, do discurso fatalista promovido pela burguesia na defesa de uma educação acrítica da qual ela se serve.

De forma menos explícita, mas igualmente relevante, a expressão de uma educação crítica também está nos cursos populares nas favelas, nas artes de grafite, nas mais diversas expressões culturais que revelam, sobretudo, algum anseio pelo rompimento com o sistema excludente (GRACIANI, 2014). Essas formas de expressão também mostram que a educação que atende às classes dominadas, desde a elaboração do conteúdo até a metodologia baseada na teoria-práticateoria, assume, além de um caráter formador e crítico, um caráter popular, mas não popular apenas pela adesão das classes populares - dessa maneira, a educação formal, como é concebida e administrada, seria naturalmente classificada como popular. Em complemento, Freire (2017, p. 113) afirma que "[...] a educação popular se pode realizar apenas no espaço da informalidade, na prática político-pedagógica fora da escola, no interior dos movimentos populares".

A educação popular, das classes populares, é feita pelas classes populares e para as classes populares, a partir de sua luta e de sua afirmação política antagônica à dominação classista estrutural, visto que é "[...] permeada pela relação entre os saberes populares e o conhecimento historicamente acumulado, pela sistematização, pela pesquisa-ação participante e pelo diálogo", o que resulta diretamente em uma formação política, cultural e ideológica das educandas e dos educandos, "[...] disseminando a ideia do fim da história e da necessidade de se adaptar à ordem" (PALUDO, 2015, p. 228).

Práxis Educativa, Ponta Grossa, v. 17, e2218510, p. 1-16, 2022 Disponível em: <https://revistas2.uepg.br/index.php/praxiseducativa $>$ 
A partir de Graciani (2014) e Paludo (2015), é possível constatar que a mais remota ideia de uma educação gerenciada por influência das classes dominantes não pode ter outro objetivo se não o de controle das classes populares. Havendo a consciência de classes, não é possível à burguesia esperar das classes populares uma submissão de maneira orgânica, ou seja, toda a articulação burguesa permanece justificada no receio de uma intervenção direta das classes populares no sistema de educação formal. Não sendo mais possível o uso da força bruta como meio de contenção, cabe ao discurso fatalista e aos mecanismos fetichistas a responsabilidade de desmantelar as lutas populares por uma educação libertadora.

A aproximação da burguesia às classes populares para propor (a continuidade de) seu modelo educacional nem sempre é ingênua, negando que seu modelo é excludente e não dá conta de todas as necessidades das classes populares, mas ela nunca comete o grave erro de expor sua deficiência estrutural. Nessa mesma direção, cabe à burguesia sustentar o ideal durkheimiano de "[...] uma mudança gradual na sociedade através da qual se removem defeitos especificos de forma a minar a base sobre a qual as reivindicações de um sistema alternativo possam ser articuladas" (MÉSZÁROS, 2008, p. 62, grifos do autor).

A classe burguesa sabe que sua autocrítica, bem como a crítica das classes populares, deve acompanhar um cenário em que a tomada de consciência popular entra em ascensão; sabe, portanto, como, para ela, a atratividade a um novo modelo deve ser eficaz. No Brasil, isso está presente na propaganda da Lei $\mathrm{N}^{\circ} 13.415 / 2017$, o que exige das classes populares, igualmente, uma contraposição, ou seja, as classes populares também precisam aderir a uma estratégia combativa que transcenda da resistência para a ação, de modo "[...] que não fiquem apenas em críticas e denúncias, mas que coloquem propostas, estabeleçam metas, objetivem um agir 'ativo' e não só a resistência, passiva" (GOHN, 2011, p. 54); em outras palavras, o papel das classes dominadas não se limita a mostrar contradições no modelo acrítico defendido pela burguesia, mas propor uma alternativa que defendam.

Essa compreensão permite, uma vez mais, evocar Graciani (2014) e sua rigorosa leitura da pedagogia social fundada, entre outros autores, em Paulo Freire, indicando que qualquer transformação substancial pode ocorrer pela prática-teoria-prática, que, nesse caso, se passa a chamar de ação-reflexão-ação. Dessa maneira, a autora permite uma clarificação da crítica de Paulo Freire ao fatalismo a partir de seu próprio método defendido, sendo atribuído a uma interpretação das dinâmicas sociais. A ação do ser, que, a posteriori, produz uma reflexão ao não gerar uma nova ação, está deixando de realizar uma transformação no ciclo que está incumbido a transformar. Reforça-se, então, que o fatalismo e o comodismo caracterizados no ser capaz de atuar em um cenário e de formular sua crítica, mas não acreditar na transformação, é automaticamente um ser incapaz de atuar com e pelas classes populares, uma vez que, independentemente do juízo que faz das classes exploradas, não pode, de forma alguma, romper com a lógica do capital, apenas escravizar-se a ela pela imobilização.

A ação da educadora e do educador popular frente ao sistema de dominação classista é, de acordo com Mészáros (2008), direcionada à reeducação das classes populares, ou seja, da contraconsciência, o que, em suas palavras, seria uma "contrainternalização". Segundo o autor, a crença popular na normalidade do sistema dá-se por uma ação do capital no processo de anexar as classes dominadas a sua própria lógica. Toda a construção social que resultou no sistema de dominação como hoje é concebido é, portanto, um processo de longo prazo e, ao mesmo tempo, inacabado. Superar a lógica do capital, então, envolve a superação do velho para propor o novo, não por meio de uma perspectiva reformista durkheimiana, como já faz a burguesia, mas pela transformação, pelo rompimento radical com a lógica do capital.

Práxis Educativa, Ponta Grossa, v. 17, e2218510, p. 1-16, 2022 Disponível em: < https:// revistas2.uepg.br/index.php/praxiseducativa> 
[...] a negação radical de toda a estrutura de comando político do sistema estabelecido deve afirmar-se, na sua inevitável negatividade predominante, na fase inicial da transformação a que se vise. Mas, mesmo nessa fase, e na verdade antes da conquista do poder político, a negação necessária só é adequada para o papel assumido se for orientada efetivamente pelo alvo global da transformação social visada, como uma bússola para toda a caminhada. Portanto, desde o início o papel da educação é de importância vital para romper com a internalização predominante nas escolhas políticas circunscritas à "legitimação constitucional democrática" do Estado capitalista que defende seus próprios interesses. Pois também essa "contrainternalização" exige a antecipação de uma visão geral, concreta e abrangente, de uma forma radicalmente diferente de gerir as funções globais de decisão da sociedade. (MÉSZÁROS, 2008, p. 61, grifos do autor).

A reflexão sobre a internalização, fundamental para a contrainternalização, necessita incluir todos os agentes envolvidos, não se limitando, nesse processo, à mera compreensão da dinâmica do capital, mas também às suas consequências imediatas que requerem reversão. Pensando nisso, em 1968, exilado no Chile, Paulo Freire escreveu sua obra de maior destaque mundial, a Pedagogia do Oprimido, na qual define as classes dominadas como oprimidas e as classes dominantes como opressoras. Freire (2019b, p. 47) conclui que a classe dominada, ou seja, os oprimidos, estão "[...] acomodados e adaptados, 'imersos' na própria engrenagem da estrutura dominadora, temem a liberdade, enquanto não se sentem capazes de correr o risco de assumi-la". Partindo dessa percepção, a ruptura com a lógica do capital demanda uma reflexão mais ampla, que não se limite ao seu sistema de dominação e nem à maneira como organicamente as classes populares têm aderido ao seu discurso, seja por compactuarem com seu modelo (o chamado fetichismo), seja pelo medo de romperem com ele.

Nesse contexto, entende-se que a subversão das classes populares deve ocorrer por diferentes camadas, nas quais se subdividem as camadas que voluntariamente aderem à lógica do capital, pela ausência da consciência de classes e pelos mecanismos fetichistas amplamente promovidos em um contexto de ascensão da agenda neoliberal; e as camadas que, mesmo conscientes de suas condições de exploradas, temem o rompimento com a lógica do capital e a responsabilidade de uma liberdade de fora da suposta generosidade do sistema.

A ação da educação, em uma perspectiva crítica e transformadora, atuaria na segunda camada mencionada anteriormente, pelo encorajamento, pela promoção da crença em uma mudança radical, pelo rompimento com a lógica do capital e pela construção de uma realidade na qual o sujeito vem a ser protagonista de sua própria história (FREIRE, 2019b). Já a primeira camada se caracteriza pela imersão aos desejos mesquinhos da burguesia, muitas vezes crente de não fazer parte da base da pirâmide, ou de fazer, mas de poder superá-la e alcançar o topo, onde é conferido espaço às classes dominantes. Nesse sentido, Freire (2019b, p. 68) busca a mudança pela práxis, a qual também resulta na conscientização, pois ocorre, “[...] em certo momento existencial dos oprimidos, uma irresistível atração pelo opressor. Pelos seus padrões de vida. Participar destes padrões constitui uma incontida aspiração. $\mathrm{Na}$ sua alienação querem, a todo custo, parecer com o opressor. Imitá-lo. Segui-lo”.

Logo nos anos de 1960, Freire tornou pública uma crítica que tem sido tomada como um dilema por educadoras e educadores comprometidas/os com a mudança real: a lógica do capital está mais entranhada nas dinâmicas sociais do que pode parecer, visto que segue discreta, porém, ao mesmo tempo, em larga progressão. Quando Mészáros (2008) enuncia a necessidade de uma contrainternalização, fica claro que a ação pela conscientização requer um comprometimento cada vez maior. Não é possível pensar nas condições materiais e nas perspectivas das classes exploradas frente à lógica do capital em um contexto de adestramento, não pela força bruta, mas pelo convencimento com o bem articulado discurso neoliberal.

Práxis Educativa, Ponta Grossa, v. 17, e2218510, p. 1-16, 2022 Disponível em: <https://revistas2.uepg.br/index.php/praxiseducativa $>$ 
Temendo a aparentemente intocável hegemonia, a burguesia busca de várias formas a consolidação de uma educação acrítica nos espaços formais de ensino, direcionando ataques em particular às manifestações de contraconsciência, de desconstrução da cultura neoliberal predominante nesses meios. Palu e Petry (2020) reforçam que tais ataques seguem seu curso por uma tentativa de despolitização do processo educativo, em outras palavras, pela reivindicação de uma neutralidade da educação crítica em um ambiente que nunca foi neutro. Com o impeachment, em 2016, o Governo Temer e seu sucessor na presidência da República Federativa do Brasil, Jair Messias Bolsonaro, desencadeiam explicitamente uma sucessão de ataques à educação crítica nas escolas, sendo a Lei No 13.415/2017 um ponto de partida.

\section{A insurreição das forças hegemônicas burguesas na educação e a Lei $\mathbf{N}^{\circ}$ 13.415/2017}

O Governo Temer iniciou acompanhado de um cenário político conturbado. A quebra das relações do PT com o Congresso e o Senado, fundamentalmente importante para o impeachment de Dilma, trouxe ao patronado maior esperança no avanço das políticas econômicas neoliberais, não tendo sequer na chefia do Executivo alguém que ao menos lá chegara com a promessa de defender os interesses das classes populares. O novo governo, por sua vez, não chegou ao poder por esse compromisso, mas por explicitamente atender à lógica do capital, colocando nos trilhos reformas como a trabalhista (Lei $N^{\circ}$ 13.467, de 13 de julho de 2017), justificando sua suposta necessidade pelos índices de desemprego. Resulta que a sanção dessa Lei não atendeu aos objetivos de empregabilidade formal, ao contrário: iniciou-se um gradual aumento da informalidade, da perda de direitos trabalhistas e de força de barganha mediante o enfraquecimento das instituições sindicais (BENEVIDES, 2018).

No campo da Educação, percebe-se, na queda da Presidenta Dilma, um ensejo para o levante de forças hegemônicas carregando consigo o discurso da despolitização nas escolas, tais como o Movimento Escola Sem Partido, liderado pelo procurador do Estado de São Paulo, Miguel Nagib, conservador e responsável por idealizar o PL 193/2016 (tendo Magno Malta como autor), intitulado com o nome do movimento e que, dentre outros aspectos, objetivou a censura do debate de ideias em campo político em sala de aula, contrariando, assim, liberdades garantidas pela LDB/1996, sendo, portanto, classificado como inconstitucional pelo Ministro Roberto Barroso, do Supremo Tribunal Federal (SILVA, 2019).

Contudo, a derrota desse Projeto de Lei não representa, em sua totalidade, qualquer enfraquecimento das forças hegemônicas contra a educação escolar. Não obstante à decisão de Barroso, o Movimento Escola Sem Partido continuou dando sequência às suas atuações nas redes sociais, intensificando, também, seu quadro de mandatários no Poder Legislativo. Ademais, Temer tampouco deixou de ser condescendente com os ataques antipopulares ao sistema educacional formal, deixando, como mais relevante legado à educação nacional, a sanção da Lei $\mathrm{N}^{\circ}$ 13.415/2017, popularmente conhecida como Novo Ensino Médio.

A partir de uma propaganda em que enfaticamente o Novo Ensino Médio é tratado como uma transição para um Ensino Médio moderno, reformula-se o sistema de execução da Base Nacional Comum Curricular (BNCC) para atender a quatro diferentes itinerários formativos a serem escolhidos pelos estudantes, os quais, com maior foco, devem integrar o núcleo básico, sendo eles: Matemática e suas Tecnologias, Ciências da Natureza e suas Tecnologias, Linguagens e suas Tecnologias, além de Ciências Humanas e Sociais Aplicadas. Em acréscimo, esse projeto também expande as ofertas de cursos técnicos e profissionalizantes, o que aparentemente causa um bem-estar a quem busca a profissionalização imediata, mas que potencializa as desigualdades sociais já existentes em âmbito escolar ao considerar " [...] os riscos de uma profissionalização precoce dos jovens pobres" (CASAGRANDE; ALONSO; SILVA, 2019, p. 412).

Práxis Educativa, Ponta Grossa, v. 17, e2218510, p. 1-16, 2022 Disponível em: < https://revistas2.uepg.br/index.php/praxiseducativa $>$ 
Indo de acordo com os interesses das classes burguesas, essa possibilidade mostra-se matematicamente atrativa, pois, ao mesmo tempo em que se qualifica a mão de obra para um mercado cada vez mais competitivo, resultando, muitas vezes, na subsunção do trabalho e na concessão de direitos, há também uma redução na concorrência pelas vagas nas universidades de maior prestígio - algo que, mesmo antes da ampliação das vagas de ensino técnico, já tem configurado desigualdade na disputa, devido à condição material das classes dominantes para financiarem boas escolas preparatórias para os processos seletivos.

Não se pode deixar de voltar aos teóricos aqui analisados, uma vez que discutem esse modelo em uma perspectiva não necessariamente reguladora das demandas do mercado de trabalho, mas também nesse modelo de ensino como um freio às possibilidades de uma tomada popular dos meios de educação formal para a emancipação das classes dominadas.

Para os poderosos é fundamental que a Educação se torne apenas um conjunto de técnicas. A redução da educação a técnicas é absolutamente indispensável para a continuidade de uma sociedade como esta. Mas na sua melhor forma a Educação é muito mais do que técnicas, a Educação é uma forma de entender o mundo com a finalidade de transformá-lo. (FREIRE; FREIRE; OLIVEIRA, 2018, p. 101).

Nesse cenário, pode-se concluir que o Novo Ensino Médio cumpre, ao mesmo tempo, dois importantes objetivos da agenda neoliberal: o adestramento do sujeito à lógica do capital e a solidificação da base piramidal do sistema de dominação, "qualificando" grandes massas das classes dominadas para servirem às elites das classes dominantes, o que em consequência também gera um gradativo esvaziamento ideológico da resistência das classes populares no ambiente acadêmico, fadado à tomada pelas elites.

Às classes populares também toca analisar o Novo Ensino Médio não como um evento extraordinário. Partindo da crítica de Mészáros a Locke no início deste artigo, é muito clara a evolução gradativa da forma como a burguesia interfere, à sua maneira, na luta dos povos explorados por sua emancipação, sendo anteriormente pela força bruta e explícita e, a partir do século XX, pelos mecanismos fetichistas, pela propaganda. Ao pensar especificamente na educação, a premissa para avaliar ameaças à luta popular é o fato de que "[...] os processos educacionais e os processos sociais mais abrangentes de reprodução estão intimamente ligados" (MÉSZÁROS, 2008, p. 25). Tal premissa permite classificar o Novo Ensino Médio como uma medida em curso, não dentro de um governo específico, mas dentro de uma lógica: a lógica do capital, na qual as classes exploradas ainda estão inseridas e da qual igualmente devem esperar novos ataques, dos mais diversos gêneros, mas com especial atenção à escola formal, sendo ela uma atrativa entidade de reprodução dessa lógica.

Essa observação também perdura ao examinarem-se as medidas evasivas do Estado em controle da burguesia, as quais assumem um caráter assistencialista, com um discurso supostamente conciliador das classes. A aceitação das classes exploradas nem sempre deve ocorrer pelos mecanismos fetichistas que resultam em uma submissão incondicional à lógica do capital, mas também pelas barganhas com as resistências mais fracas, também corruptíveis.

[...] caso não se valorize um determinado modo de reprodução da sociedade como o necessário quadro de intercâmbio social, serão admitidos, em nome da reforma, apenas alguns ajustes menores em todos os âmbitos, incluindo o da educação. As mudanças sob tais limitações, apriorísticas e prejulgadas, são admissíveis apenas com o único e legítimo objetivo de corrigir algum detalhe defeituoso da ordem estabelecida, de forma que sejam mantidas intactas as determinações estruturais fundamentais da sociedade como um todo, em conformidade com as exigências inalteráveis da lógica global de um determinado sistema de reprodução. Podem-se ajustar as formas pelas quais uma multiplicidade de interesses particulares conflitantes se deve conformar com a regra geral preestabelecida da

Práxis Educativa, Ponta Grossa, v. 17, e2218510, p. 1-16, 2022 Disponível em: <https://revistas2.uepg.br/index.php/praxiseducativa $>$ 
reprodução da sociedade, mas de forma nenhuma pode-se alterar a própria regra geral. (MÉSZÁROS, 2008, p. 25-26, grifos do autor).

Portanto, mesmo na propaganda em que supostamente se espera uma melhor realidade às classes populares que, logo no Ensino Médio já poderiam aderir à formação para a inserção imediata ao mercado de trabalho, o Estado não exerce mais do que seu poder de barganha na tentativa de manter a ordem frente a pequenos possíveis levantes populares. A burguesia, porém, não concebe uma alteração à regra de reprodução das desigualdades que mantém sua subsistência. Dessa maneira, o Novo Ensino Médio, ainda que não possa erradicar a luta das classes populares por sua emancipação, não marcará um ponto final do levante burguês pela manutenção da lógica do capital; assim, novas medidas certamente serão tomadas.

Seria necessária uma extensa análise conjuntural para afirmar qual medida a burguesia tomaria pela garantia da lógica do capital, visto que sua articulação está diretamente atrelada ao comportamento dos explorados frente às suas condições. No contexto do Novo Ensino Médio, muitas críticas surgem no que se refere à manutenção de sua infraestrutura sugerida, tal como aponta Ferretti (2018), o que implica aspectos quantitativos como a contratação, a qualificação e a adequação de docentes aos escopos e aos cronogramas propostos, cujos desafios são potencializados, dado que o currículo do Ensino Médio também passaria a ser executado em período integral. A incerteza também se estende em aspectos qualitativos, considerando aspectos logísticos que envolvem a capacitação de docentes para áreas muito específicas em um período de tempo questionável para tal fim, levando em conta também que há números ainda pouco certos no que se refere às escolhas de estudantes por determinados itinerários formativos e cursos técnicos - como muitos desdobramentos não podem oferecer de antemão um planejamento claro a se executar, a consequência pode ser uma formação docente muito precária para a atuação em áreas de conhecimento diversificadas, influenciando, também, o cumprimento do núcleo de disciplinas de base.

É importante esclarecer, todavia, que mesmo gerando dúvidas principalmente em seus aspectos técnicos de gerenciamento dos novos currículos formativos, a Lei N ${ }^{\circ}$ 13.415/2017 não pode ser discutida sem que seja considerada a progressão da agenda neoliberal dentro do sistema educacional brasileiro. Na verdade, as políticas neoliberais vêm antes mesmo da precarização da educação. Mesmo nos discursos mediáticos que, com a referida Lei, é proposto modernizar o sistema educacional, o desprestígio da profissão docente e a reprodução da lógica classista de separação entre classes dominantes e dominadas mostram uma face do "Novo" Ensino Médio que é muito bem mascarada pela propaganda. Gomes e Sampaio (2021) propõem uma análise comparativa entre o sistema francês, um dos quais a Lei $\mathrm{N}^{\circ}$ 13.415/2017 supostamente tem como base de criação, segundo a propaganda do governo. Um dos equívocos apontados pelos autores no que se refere ao currículo profissionalizante, que, no sistema francês (certificado conhecido como baccalauréat professionne), visa à formação para o ingresso ao Ensino Superior, há cursos cujas áreas são relacionadas ao setor administrativo, ao passo que a proposta do currículo técnicoprofissionalizante na Lei $N^{\circ}$ 13.415/2017 é a abreviação ao mercado de trabalho. Segundo os autores,

[...] as competências adquiridas no ensino médio [com a Lei № 13.415/2017] não necessariamente seriam aproveitadas em um exame de admissão ao ensino superior como ocorre com o aproveitamento do certificado Baccalauréat, à parte de que, como já mencionado, o ensino técnico-profissionalizante tampouco tem por objetivo mediar o ingresso do aluno ao ensino superior e, se assim fosse, a menos que as taxas de ingresso de alunos desprivilegiados às cadeiras mais disputadas dos cursos de caráter profissionalizante aumentassem a níveis satisfatórios, essa alternativa, se muito, ampliaria a demanda pelos cursos que já têm forte adesão por parte de estudantes menos privilegiados em instituições de ensino superior de baixa qualidade, inflando diversos

Práxis Educativa, Ponta Grossa, v. 17, e2218510, p. 1-16, 2022 Disponível em: < https:// revistas2.uepg.br/index.php/praxiseducativa> 
empreendimentos beneficiados pelas parcerias público-privadas de financiamento estudantil. (GOMES; SAMPAIO, 2021, p. 2075).

Nesse sentido, é possível compreender que não apenas as classes dominantes logram êxito no esvaziamento do pouco espaço que os mais pobres ocupam nas universidades de maior prestígio, como também canalizam os esforços dos que buscam a formação de nível superior aos seus próprios empreendimentos, tendo órgãos de gestão pública muitas vezes como facilitadores para tanto.

Da mesma maneira que ocorreu com Locke, o pai do liberalismo que enriqueceu em uso de sua influência no setor público, essa mesma realidade repete-se e a Lei $\mathrm{N}^{\circ} 13.415 / 2017$ pode mostrar que, mesmo com a narrativa neoliberal que responsabiliza o Estado pela falta de prosperidade no setor privado, grandes instituições privadas de Ensino Superior nunca foram tão beneficiadas por esse mesmo Estado. Apple (2005) também se debruça sobre essa questão ao indicar que o neoliberalismo se modernizou não pela crítica vazia ao Estado, mas por seu aproveitamento enquanto entidade necessária. Em outras palavras, a ação política das classes dominantes (ainda que rechacem esse termo) é orientada por seu explícito interesse pelo Estado, reivindicando maior controle sobre ele.

A combinação dos principais fatores que determinam a divisão classista em âmbito escolar a partir do Novo Ensino Médio resulta no que, em outros momentos da história, se avaliou como processo de despolitização da educação brasileira. Gadotti (2012) aponta a Lei No 5.692, de 11 de agosto de 1971, que objetivou uma reforma curricular no primeiro e no segundo graus, tendo como principal diferenciação do currículo vigente naquele período a obrigatoriedade do ensino profissionalizante. O autor recorda momentos que se pode comparar com o contexto em que a Lei $\mathrm{N}^{\circ} 13.415 / 2017$ foi defendida, bem como suas narrativas, tais como as experiências de um país central (Estados Unidos da América, em 1971) como base, bem como a possibilidade de acesso imediato ao mercado de trabalho por um grupo demasiadamente carente de boas perspectivas no que tange à vida profissional.

Nesse cenário, a atratividade pelo acesso imediato ao mercado, tal como em 1971, só potencializaria a abdicação aos currículos formativos cujas disciplinas focam, tal como um preparo ao processo seletivo para o Ensino Superior, a formação do pensamento crítico, dado que a escolha pelo currículo de formação técnico-profissionalizante implica uma gradativa precarização de disciplinas do campo das Ciências Sociais e Humanas mediante redução da sua demanda, visto que seu foco está em outro currículo (BRASIL, 2017).

Dessa forma, a grande diferença da inserção da formação profissional obrigatória na Lei $\mathrm{N}^{\circ} 5.692 / 1971$, para a oferta de formação técnica e profissional na Lei $\mathrm{N}^{\circ} 13.415 / 2017$, é a sensação de modernização de uma em relação à outra pela elegibilidade. Essa elegibilidade, porém, não pode ser dicotomizada das condições materiais de quem com ela conta, mostrando uma óbvia tendência de que os mais pobres elejam o currículo técnico-profissionalizante e, movidos pelas mesmas condições materiais, resistam cada vez menos à predominante dominação de herdeiros das classes mais abastadas dos espaços mais almejados nas universidades.

Não há garantias, no entanto, de que as vagas no mercado de trabalho possam ser imediatamente preenchidas por quem obter a formação técnica-profissionalizante logo após a conclusão do Ensino Médio; e se isso ocorrer, também não há garantias de que as expectativas desse público sejam atendidas. O Novo Ensino Médio tem grandes chances de fracassar frente à avaliação das classes dominadas que, de alguma forma, ainda estão crentes nele, e isso não será determinado pelo Pisa, nem por qualquer outra entidade avaliadora de desempenho da educação nacional, mas pelo pragmatismo. Nesse cenário, mesmo um atrativo modelo de educação acrítica

Práxis Educativa, Ponta Grossa, v. 17, e2218510, p. 1-16, 2022 Disponível em: <https://revistas2.uepg.br/index.php/praxiseducativa $>$ 
colaboraria para com o discurso supostamente progressista do caráter do Novo Ensino Médio, visto que mesmo a qualificação para o mercado de trabalho talvez não seja muito eficaz e, o que se tem como certo frente à inserção de grandes massas disputando postos escassos, é que até mesmo a educação profissionalizante dificilmente bastará para suprir os anseios dos mais pobres por alguma estabilidade financeira.

A Lei No 13.415/2017, prevista para ser implantada em 2022 e ter implementação concluída no fim do Plano Nacional de Educação (PNE) mais recente, em 2024 (CASAGRANDE; ALONSO; SILVA, 2019), marcará o êxito ou o fracasso de uma articulação neoliberal. Seu muito provável fracasso leva a aceitar-se a hipótese de que o Estado, em poder da burguesia, sustente um novo discurso, com uma nova proposta, articulada e fortemente defendida por influenciadores digitais, religiosos e mandatários atuantes no Congresso Federal e no Senado. Até o momento, está descartada a hipótese da insurreição de um projeto educacional nos moldes defendidos por Locke frente à legislação brasileira e ao novo contexto social, porém o mesmo modelo de educação acrítica deve perdurar, visto que este segue a lógica do capital.

\section{Considerações finais}

Com base na análise teórica, sobretudo na crítica de Mészáros a Locke, é possível interpretar a Lei $N^{\circ}$ 13.415/2017 não como uma anomalia, mas como uma articulação da agenda neoliberal, outorgando, assim, à lógica do capital uma perspectiva quase progressista, mas que nada mais faz do que obedecer estritamente a um reformismo durkheimiano do sistema capitalista, sem romper com as estruturas de reprodução de desigualdades. Esse sistema, como já tratado, é condição primordial de subsistência das classes dominantes, devendo igualmente considerar as desigualdades sociais, que, diretamente, resultam na competitividade da qual também se beneficiam apenas as classes dominantes.

A apropriação de autores aqui utilizados permitiu uma boa interpretação dessa lógica, além do que seria a melhor forma de contraposição a ela, mostrando também como a crítica do filósofo húngaro ao texto do iluminista inglês se mantém atual, possibilitando um entendimento de qual é o papel da educadora e do educador popular neste novo cenário: o mesmo que sempre foi frente a modelos educacionais não concebidos para e pelas classes populares, um papel de ação-reflexãoação, ou seja, a crítica que transcende e mobiliza para uma transformação real. Essa dialética deverá ser utilizada não apenas em um cenário de enfrentamento às mazelas trazidas pelo Novo Ensino Médio, mas também para quaisquer propostas vindas do Movimento Escola Sem Partido, institucionalizadas ou não, igualmente às outras propostas que virão como "renovadoras" sempre que a burguesia falhar.

\section{Referências}

APPLE, M. W. Para além da lógica do mercado: compreendendo e opondo-se ao neoliberalismo. Rio de Janeiro: DP\&A, 2005.

ARAÚJO, M. L. H. S.; TENÓRIO, R. M. Resultados brasileiros no PISA e seus (des)usos. Estudos em avaliação educacional, São Paulo, v. 28, n. 68, p. 344-380, maio/ago. 2017. DOI: https://doi.org/10.18222/eae.v28i68.4553

BAUER, C. Educação, terra e liberdade: princípios educacionais do MST em perspectiva histórica. 2. ed. Jundiaí: Paco Editorial, 2016. 
BENEVIDES, S. C. Impactos da reforma trabalhista no modelo de custeio das organizações sindicais. Revista Tribunal Regional do Trabalho, $3^{\text {a }}$ Região, Belo Horizonte, v. 64, n. 97, p. 167-183, jan./jun. 2018.

BITTAR, M.; BITTAR, M. História da educação no Brasil: a escola pública no processo de democratização da sociedade. Acta Scientiarum. Education, Maringá, v. 34, n. 2, p. 157-168, jul./dez. 2012. DOI: https://doi.org/10.4025/actascieduc.v34i2.17497

BRASIL. Lei $\mathbf{N}^{\circ}$ 9.394, de 20 de dezembro de 1996. Estabelece as diretrizes e bases da educação nacional. Brasília: Presidência da República, Casa Civil, Subchefia para Assuntos Jurídicos, [1996]. Disponível em: http://www.planalto.gov.br/ccivil 03/leis/19394.htm. Acesso em: 2 fev. 2022.

BRASIL. Lei $\mathrm{N}^{\circ}$ 13.415, de 16 de fevereiro de 2017. Altera as Leis $\mathrm{N}^{\text {os }} 9.394$, de 20 de dezembro de 1996, que estabelece as diretrizes e bases da educação nacional, e 11.494, de 20 de junho 2007, que regulamenta o Fundo de Manutenção e Desenvolvimento da Educação Básica e de Valorização dos Profissionais da Educação, a Consolidação das Leis do Trabalho - CLT, aprovada pelo Decreto-Lei no 5.452, de 1o de maio de 1943, e o Decreto-Lei no 236, de 28 de fevereiro de 1967; revoga a Lei no 11.161, de 5 de agosto de 2005; e institui a Política de Fomento à Implementação de Escolas de Ensino Médio em Tempo Integral. Diário Oficial da União: seção 1, Brasília, DF, n. 35, p. 1-3, 17 fev. 2017.

CASAGRANDE, A. L.; ALONSO, K. M.; SILVA, D. G. Base nacional comum curricular e Ensino Médio: reflexões à luz da conjuntura contemporânea. Diálogo Educacional, Curitiba, v. 19, n. 60, p. 407-425, 2019. DOI: https://doi.org/10.7213/1981-416X.19.060.AO05

DAL RI, N. M.; VIEITEZ, C. G. Educação democrática e trabalho associado no movimento dos trabalhadores rurais sem terra e nas fábricas de autogestão. São Paulo: FAPESP, 2008.

FERRETTI, C. J. A reforma do Ensino Médio e sua questionável concepção de qualidade da educação. Estudos Avançados, São Paulo, v. 32, n. 93, p. 25-42, 2018. DOI: https://doi.org/10.5935/0103-4014.20180028

FREIRE, P. Pedagogia da autonomia: saberes necessários à prática educativa. 59. ed. Rio de Janeiro, São Paulo: Paz \& Terra, 2019a.

FREIRE, P. Pedagogia do oprimido. 69. ed. Rio de Janeiro, São Paulo: Paz e Terra, 2019b.

FREIRE, P. Política e educação. In: FREIRE, A. M. A. (org.). Política e educação. 3. ed. Rio de Janeiro: Paz e Terra, 2017.

FREIRE, P.; FREIRE, A. M. A.; OLIVEIRA, W. F. Pedagogia da solidariedade. 3. ed. Rio de Janeiro, São Paulo: Paz e Terra, 2018.

GADOT'TI, M. Educação e poder: introdução à pedagogia do conflito. 16. ed. São Paulo: Cortez, 2012.

GIOLO, J. A educação a distância e a formação de professores. Educação \& Sociedade, Campinas, v. 29, n. 105, p. 1211-1234, 2008. DOI: https://doi.org/10.1590/S0101$\underline{73302008000400013}$

GOHN, M. G. Educação não formal e cultura política: impactos sobre o associativo do terceiro setor. 2. ed. São Paulo: Cortez, 2011. 
GOMES, M. C. O.; SAMPAIO, M. G. O Ensino Médio no Brasil e na França: considerações sobre a Lei 13.415/2017 a partir de uma análise comparativa. Revista on line de Política e Gestão Educacional, Araraquara, v. 25, n. 4, p. 2066-2079, 2021. DOI: https://doi.org/10.22633/rpge.v25iesp.4.15940

GRACIANI, M. S. S. Pedagogia social. São Paulo: Cortez, 2014.

HERNANDES, P. R. A reforma do Ensino Médio e a produção de desigualdades na educação escolar. Educação, Santa Maria, v. 44, n. 1, p. 1-19, 2019. DOI: https://doi.org/10.5902/1984644434731

LIMA, M. A educação profissional no governo Dilma: Pronatec, PNE e DCNEMs. Revista Brasileira de Política e Administração da Educação, Brasília, v. 28, n. 2, p. 495-513, 2012. DOI: $\underline{\text { https://doi.org/10.21573/vol28n22012.37418 }}$

MARX, K. O capital: crítica da economia política: o processo de produção do capital. São Paulo: Nova Cultural, 1996, Livro I, Volume 1.

MEKSENAS, P. Sociologia da educação: Introdução ao estudo da escola no processo de transformação social. 17. ed. São Paulo: Loyola, 2014.

MÉSZÁROS, I. A educação para além do capital. 2. ed. Tradução Isa Tavares. São Paulo: Boitempo, 2008.

PALU, J.; PETRY, O. J. Neoliberalismo, globalização e neoconservadorismo: cenários e ofensivas contra a Educação Básica pública brasileira. Práxis Educativa, Ponta Grossa, v. 15, n. 1, p. 1-21, 2020. DOI: https://doi.org/10.5212/PraxEduc.v.15.15317.063

PALUDO, C. Educação popular como resistência e emancipação humana. Cadernos Cedes, Campinas, v. 35, n. 96, p. 219-238, 2015. DOI: https://doi.org/10.1590/CC0101-32622015723770

PINI, F. R. Educação popular em direitos humanos no processo de alfabetização de jovens, adultos e idosos: uma experiência do projeto mova-brasil. Educação em Revista, Belo Horizonte, v. 35, e214479, p. 1-23, 2019. DOI: https://doi.org/10.1590/0102-4698X214479

SAMPAIO, M. N. Educação de jovens e adultos: Uma história de complexidade e tensões. Práxis Educacional, Vitória da Conquista, v. 5, n. 7, p. 13-27, jul./dez. 2009.

SILVA, T. P. Caso da deputada estadual Ana Caroline Campagnolo com traços do projeto Escola Sem Partido: uma análise à luz da teoria libertária de Paulo Freire. Revista Diálogo Jurídico, Fortaleza, v. 18, n. 2, p. 35-45, 2019.

XAVIER, C. F. História e historiografia da educação de jovens e adultos no Brasil inteligibilidades, apagamentos, necessidades, possibilidades. Revista Brasileira de História da Educação, Maringá, v. 19, n. 1, p. 1-24, 2019. DOI: https://doi.org/10.4025/rbhe.v19.2019.e068

Recebido em 23/07/2021

$V$ ersão corrigida recebida em 23/01/2022

Aceito em 27/01/2022

Publicado online em 07/02/2022

Práxis Educativa, Ponta Grossa, v. 17, e2218510, p. 1-16, 2022 Disponível em: <https://revistas2.uepg.br/index.php/praxiseducativa> 